\title{
13. ZITIERTE LITERATUR NACH 1600
}

ARCHIV český ěili staré písemné pamatký české í moravské, sebrané z archivu domácích í cizích. VII-VIII. Prag 1887-88.

Winfried Baumann, Die Literatur des Mittelalters in Böhmen. Deutsch-lateinisch-tschechische Literatur vom 10. bis zum 15. Jahrhundert (Veröffentlichungen des Collegium Carolinum 37). München-Wien 1978.

Michael Beneim's Buch von den Wienern 1462-1465. Zum ersten Mahle hrsg. von Theodor G. von Karajan. Wien 1843.

Michael Benerm - Die Gedichte des Michel Beheim 2. Hrsg. von Hans Gille und Ingeborg Spriewald (Deutsche Texte des Mittelalters 64) Berlin 1970.

Tilman Berger, Tschechischunterricht in der Habsburgerfamilie ab 1526. Wiener Slavistisches Jahrbuch 46 (2000) 61-71.

Tilman Berger, Der alttschechische „Umlaut“ - ein slavisch-deutsches Kontaktphänomen? in: Festschrift für Klaus Trost zum 65. Geburtstag. München 1999, 19-27.

Günter Belluann, Slavoteutonica. Lexikalische Untersuchungen zum slawisch-deutschen Sprachkontakt im Ostmitteldeutschen (Studia linguistica Germanica 4). Berlin-New York 1971.

Margarete Bieder, Das polnisch-deutsche Vokabularium aus der Krakauer Offizin des H. Vietor, gedruckt im Jahre 1539. Wien Diss. 1975.

Ernst BIRK, Urkunden-Auszüge zur Geschichte Kaiser Friedrichs des III. in den Jahren 1452-1467 aus bisher unbenutzten Quellen. AfÖG 10 (1853) 369-443.

Mirjam Boнатčová, Česko-německá konverzace pro kupce. K počát kům tistených učebnic (1531, 1540). Sbornik národniho muzea v Praze C/XXI/3 (1976) 117-158.

Václav BoK, Slovnik středovéké néměiny pro historiky. Budweis 1995.

Hildegard Boková, Beobachtungen zur Prager Druckersprache des 16. Jahrhunderts, in: Fata Libellorum. Festschrift für Franzjosef Pensel (= Göppinger Arbeiten zur Germanistik 648) Göppingen 1999, 11-20.

Tilo Brandis, Die Codices in scrinio der Staats- und Universitätsbibliothek Hamburg (Katalog Der Handschriften der Staats- und Universitätsbibliothek Hamburg VII) Hamburg 1972 .

Vincenz Brande, Glossarium illustrans bohemico-moravicae historiae fontes. Brünn 1876.

Heinz Brandu, Die tschechische Lexikographie des 16. Jahrhunderts. Diss. Breslau 1939.

Charles Moïse Briquet, Les filigranes. Paris usw. 1907

Pavel BronskÝ, Néznamé Hankovo falzum v knihovne Národního muzea. Sborník národního muzea v Praze CXXX, 1 (1986) 21-28.

Ludwig Brunner, Eggenburg. Geschichte einer niederösterreichischen Stadt 1-2. Eggenburg 1933. 
Barbara Bruzzone, Fremdsprachen in der Adelserziehung des 17. Jahrhunderts: Die Sprachbücher von Juan Angel de Sumarán, in: Die Volkssprachen als Lerngegenstand im Mittelalter und in der frühen Neuzeit. Akten des Bamberger Symposiums am 18. und 19. Mai 2001. Hrsg. von Helmut GLÜcK ( = Die Geschichte des Deutschen als Fremdsprache 3) Berlin - New York 2002, 37-46.

Rudolf BüTTNER, Burgen und Schlösser zwischen Wienerwald und Leitha (Niederösterreich 1,1) Wien 1966.

Aniceto ChiAppini, Reliquie letterarie Capestranesi. Storia - codici - carte - documenti (Bulletino della R. deputazione Abruzzese di storia patria Ser. III) Aquila 1927.

Josef Chyel, Regesta chronologico-diplomatica Friderici IV. romanorum regis. Auszug aus den imk. K. geheimen Hofarchive zu Wien sich befindenden Reichsregisterbüchern vom Jahre 1440-1493. Wien 1838 (Nachdr. Hildesheim 1962)

Franz ClaEs, Bibliographisches Verzeichnis der deutschen Vokabulare und Wörterbücher, gedruckt bis 1600. Hildesheim-New York 1977

Michael Denis, Wiens Buchdruckergeschicht bis MDLX. Wien 1782.

Michael Denis, Nachtrag zu seiner Buchdruckgeschicht Wiens. Wien 1793.

Lorenz Diefenbach, Glossarium Latino-Germanicum mediae et infimae aetatis e codicis manuscriptis et impressis. Frankfurt/M. 1857.

Lorenz Diefenbach, Mittellateinisch-hochdeutsch-böhmisches Wörterbuch, nach einer Handschrift vom Jahre 1470. Frankfurt/M. 1846.

Joseph Doвrowsky, Geschichte der Böhmischen Sprache und ältern Literatur. Ganz umgearb. Aufl. Prag 1818.

Richard Kurt Donin, Wildegg. Wien 1927.

Charles Ducange, Glossarium mediae et infimae Latinitatis. (Paris) 1883/87. Bd. I-X.

Ernst Eichler, Etymologisches Wörterbuch der slawischen Elemente im Ostmitteldeutschen (Dt. Akad. Wiss. Schriftenreihe des Instituts für sorbische Volksforschung in Bautzen = Spisy Instituta za serbski ludospyt 29). Bautzen 1965.

Helmut Engelbrecht, Geschichte des österreichischen Bildungswesens. Erziehung und Unterricht auf dem Boden Österreichs. 1. Von den Anfängen bis in die Zeit des Humanismus. Wien 1982.

Ernst Englisch - Gerhard JARitz, Das tägliche Leben im spätmittelalterlichen Niederösterreich (Wissenschaftliche Reihe Niederösterreich 19-21).St. Pölten - Wien 1976

Tönnies Fennis, Low German Manual of Spoken Russian, Pskov 1607. Ed. L.L. Hammerich and Roman Jakobson. II. Copenhagen 1970

Heinrich Fichtenau, Die Lehrbücher Maximilians I. und die Anfänge der Frakturschrift. Hamburg 1961.

Heinrich Fichtenau, Maximilian und die Sprache, in: Beiträge zur neueren Geschichte Österreichs (= Veröffentlichungen des IfÖG 20 (1974) 32-46.

Václav FlajšHans, Nás jazyk matěrsky. Dejíny jazyka českého a vývoj spisovné slovenštiny. Prag 1924.

Václav FlaJšHans, Klaret a jeho družina 1-2 (Sbirka pramenů k poznáni literárniho života v Čechách, na Moravě a ve Slezsku 1/1/ Corpus Glossariorum Bohemicorum 1). Prag 19261928. 
Vilmos Fraknoi, A Hunyadiak és a Jagellók kora (1440-1526) (A magyar nemzet története 4). Budapest 1896.

Johannes Fried, Kunst und Kommerz. Über das Zusammenwirken von Wissenschaft und Wirtschaft im Mittelalter, vornehmlich am Beispiel der Kaufleute und Handelsmessen. (Schriften des Historischen Kollegs. Vorträge 32) München 1993

Jan Gebaukr, Slovnik staročeský 1-2. Prag 1970.

Geschichte der Österreichischen Nationalbibliothek. Hrsg. von Josef Stumvvoll 1 (Museion N.F. 2/3/1) Wien 1968.

Helmut GLÜck, Die Anfänge des DaF-Unterrichts. Deutsch als Fremdsprache im Mittelalter und in der frühen Neuzeit. Mitteilungen des deutschen Germanistikverbandes 47 (2000) $166-185$.

Hans GöBL, Die Sprachensituation in der Donaumonarchie, in: Sprachen in Europa. Sprachsituation und Sprachpolitik in europäischen Ländern. Hrsg. von Ingeborg OHnHEISER, Manfred KienpointneR, und Helmut Kацв (= Innsbrucker Beiträge zur Kulturwissenschaft 30). Innsbruck 1999, 33-58.

Peter P. Golden, Codex Cumanicus, in: Central Asian monuments. Ed. By Hasan B. Paksoy. Istanbul 1992, 33-63.

Nataša GoLoB, Kadelne iniciale v dveh volumnih frančiškanskega graduala. Zbornik za umetnostno zgodovino s. n. XXXVIII (Ljubljana 2002) 154-185.

Theodor GoTTLieB, Büchersammlung Kaiser Maximilians I. Mit einer Einleitung über älteren Bücherbesitz im Hause Habsburg (Die Ambraser Handschriften. Beitrag zur Geschichte der Wiener Hofbibliothek 1). Leipzig 1900.

Jakob und Wilhelm Grimm, Deutsches Wörterbuch I-XVI. Leipzig 1854-1954.

Helmuth Grössing, Die Wiener Universität im Zeitalter des Humanismus von der Mitte des 15. Bis zur Mitte des 16. Jahrhunderts, in: Das alte Universitätsviertel in Wien, 13851985. (= Schriftenreihe des Universitätsarchivs 2) Wien 1985, 37-45.

Karl Grossmann, Die Frühzeit des Humanismus in Wien bis zu Celtis Berufung 1497. Jahrbuch für Landeskunde von Niederösterreich N. F. 22 (1929) 150-325.

Klaus GrubuÜller, Vocabularius Ex quo. Untersuchungen zu lateinisch-deutschen Vokabularen des Spätmittelalters (Münchener Texte und Untersuchungen zur deutschen Literatur des Mittelalters 17). München 1967.

Heinrich Hänger, Mittelhochdeutsche Glossare und Vokabulare in schweizerischen Bibliotheken bis 1500 (Quellen und Forschungen zur Sprach- und Kulturgeschichte der germanischen Völker N.F. 44). Berlin-New York 1972.

Anna Katharina Hahn, Die Historienbibel Cod. 8 in scrin. Der Staats- und Universitätsbibliothek Hamburg (Codices illuminati medii aevi 47). München 1997.

Alois Haidinger, Katalog der Handschriften des Augustiner Chorherrenstiftes Klosterneuburg 1 (DS Österr. Akad. Wiss., phil.-hist.Kl.168 = Veröffentlichungen der Kommission für Schrift- und Buchwesen des Mittelalters II/2/1). Wien 1983.

Alois Haidinger, Drei Determinations-Ankündigungen aus dem Stift Klosterneuburg. (Wiener Jahrbuch für Kunstgeschichte $46 / 47$ (1993/94) 237-244, 425-428.

Alois Haidinger, Verborgene Schönheit. Die Buchkunst im Stift Klosterneuburg. Klosterneuburg/Wien 1998. 
Matilda Науекоvá, Dejiny slovenských slovníkov do roku 1945. Preßburg 1979

Paul Joachim Heinig, Kaiser Friedrich III. (1440-1493). Hof, Regierung und Politik 1-3 (Forschungen zur Kaiser- und Papstgeschichte des Mittelalters. Beih. zu J.F.BÖHMERS Regesta Imperii 17) Köln-Weimar-Wien 1997.

Gernot Heiss, Standeserziehung und Schulunterricht. Zur Bildung des niederösterreichischen Adeligen in der frühen Neuzeit, in: Adel im Wandel. Politik, Kultur, Konfession 15001700. Niederösterreichische Landesausstellung. Rosenburg 1990, 391-407.

František Hoffmann, Soupis rukopisů knihovny kláštera Premonstrátů Teplá (Catalogus codicum manu scriptorum bibliothecae monasterii Teplensis ordinis Praemonstratensis I-II). Prag 1999.

Johannes Hofer, Johannes Kapistran. Ein Leben für die Reform der Kirche I/II (Bibliotheca Franciscana 1-2) Neue, bearb. Aufl. Heidelberg 1964/65.

Günter Holtus und Wolfgang Schweikard, Elemente gesprochener Sprache in in einem venezianischen Text von 1424: Das italienisch-deutsche Sprachbuch des Georg von Nürnberg, in: Gesprochenes Italienisch in Geschichte und Gegenwart. Hrsg. von Günter Holtus und Edgar RadTKe (= Tübinger Beiträge zur Linguistik 252). Tübingen 1985, $354-376$.

Milada Homolková, Möglichkeiten der Erkennung und Beschreibung lexikalisch-semantischer Strukturen (am Beispiel des Alttschechischen). Wiener Slavistisches Jahrbuch 46 (2000) 175-184.

Maria Hornung, Mundartkunde Osttirols. Eine dialektgeographische Darstellung mit volkskundlichen Einblicken in die altbäuerliche Lebenswelt (Studien zur österreichisch-bairischen Dialektkunde 3). Wien 1964.

Incunabula Short-Title Catalogue (ISTC Database). British Library London (1980 ff.).

Ignatij Vikentijević JaGić, Rez. von F, Menčiks Vocabularium latinobohemicum Posoniensis. Archiv für slavische Philologie 14 (1893) 308-311.

Miklós JósıKa, A esehek magyarországban. Korrajz I. Mátyás király idejéböl. 4. Pest 1857

Josef Jungmann, Historie literatury české. Prag 1825.

Josef Jungmann, Slownjk ěesko-némecký I-V. Prag 1835/39.

Alfred Karnein, Deutsch als Fremdsprache im 15. Jahrhundert: Das Sprachbuch Meister Jörgs. Jahrbuch Deutsch als Fremdsprache 2 (1976) 1-13.

Katalog - 850 Jahre St. Stephan. Symbol und Mitte in Wien 1147-1997 (Historisches Museum der Stadt Wien, Sonderausstellung 226) Wien 1997.

Katalog - Der Aufstieg eines Kaisers: Maximilian I. von seiner Geburt bis zur Alleinherrschaft. (Ausstellungskatalog). Wiener Neustadt 2000.

Katalog Friedrich III. Kaiserresidenz Wiener Neustadt (Katalog des Niederösterreichischen Landesmuseums N.F. 29) Wiener Neustadt 1966.

Katalog Die Kuenringer. Das Werden des Landes Niederösterreich. Zwettl 1981.

Katalog Od gotiky k renesanci. Výtvarná kultura Moravy a Slezska 1400-1550, II. Brünn 1999.

Katalog der Österreichischen Nationalbibliothek. Ambraser Kunst- und Wunderkammer. Die Bibliothek. Wien 1965. 
Elżbieta KĘDELSKA, Łacińsko-polskie słowniki drukowane pierwszej połowy XVI wieku i ich stosunek do źródeł czeskich (Monografie slawistyczne 53) Breslau (usw.) 1986.

Jiři KEJR, Die Anfänge der Stadtverfassung und des Stadtrechts in den Böhmischen Ländern, in: Die deutsche

Ostsiedlung des Mittelalters als Problem der europäischen Geschichte. Reichenau-Vorträge $1970 / 72$,

hrsg. von W. Schlesinger (= Vorträge und Forschungen XVII) Sigmaringen 1975, 439-470.

Károly Kisfaludi, Minden munkai ... szerkeszté Toldy Ferencz. 1. Pest 1859.

Herbert KöLlner, Zur kunstgeschichtlichen Terminologie, in: Zur Katalogisierung mittelalterlicher und neuerer Handschriften (= Zeitschrift für Bibliothekswesen und Bibliographie. Sonderheft). Frankfurt/Main 1963, 138-154.

Peter O. MứleEr, Deutsche Lexikographie des 16. Jahrhunderts. Konzeptionen und Funktionen frühneuzeitlicher Wörterbücher (Texte und Textgeschichte 49) Tübingen 2001

György KóKay, Geschichte des Buchhandels in Ungarn (Geschichte des Buchhandels III) Wiesbaden 1990.

Martin Kólar, Českomoravská heraldika 1. Čast vseobečná,. Upravil August SedlačEK. Prag 1902.

M. Kома́Reк, Alttschechische Gebete im Itinerarium Johannes Butzbachs, in: Deutsch-tschechische Beziehungen im Bereich der Sprache und Kultur. Aufsätze und Studien. Hrsg. von B. HavraneK und R. Fischer (= Abh. Sächs. Akad. Wiss., philol.-hist. Kl. 57/2). Leipzig 1965) 73-86

Eberhard Kranzmayer, Die bairischen Kennwörter und ihre Geschichte. Wien 1960

Josef Krása, Die Handschriften König Wenzels IV. Wien 1971.

Josef Krása, České illuminované rukopisy 13. - 16. stoleti. Prag 1990.

Josef Krása, Knižní malî́ství, in: Pozdnĕ gotické umĕní v Čechách. Prag 1978.

Jitka Křksálková, Il Vocabolario Quadrilingue Latino-Veneto-Ceco-Tedesco (Cod.Pal.Lat. 1789). Bergamo 1984.

Jitka KřEsálková, Na okraj českých slovníků z XV. a XVI. století. Slavia. Časopis pro slovanskou filologii 66 (1997) 35-43.

Kuun, Géza, Codex Cumanicus bibliothecae ad templum divi Marci Venetiarum. Primum ex integro ed., prolegomenis notis et cum pluribus glossariis instruxit. Budapest 1880.

Peter Lambeck - Petri Lambecii Hambvrgensis...Commentariorvm de Augusta Bibliotheca Caesarea Vindobonensi liber II. Wien 1669.

Lexicon - Latinitatis medii aevi Lexicon Bohemorum s. SLovvík středověké

Alphons Lhotsky, Die Wiener Artistenfakultät 1365-1497 (SB Österr. Akad. Wiss., philhist.Kl. 247/2). Wien 1965.

Alphons Lhoтsкy, Die Bibliothek Kaiser Friedrichs III. MIÖG 58 (1950) 124-135.

Alphons Lhotsky, AEIOV. Die „Devise“ Kaiser Friedrichs III. und sein Notizbuch. MIÖG $60=$ Festgabe für August LöHr (1952) 155-193.

Alphons Lhotsky und K. Ferrari d Occhieppo, Zwei Gutachten Georgs von Peuerbach über Kometen (1456 und 1457). MIÖG 68 = Festgabe für Leo SantIFalLer (1960) 266-290. 
Alphons Lнотsку, Quellenkunde zur mittelalterlichen Geschichte Österreichs (MIÖG Erg. Bd. XIX) Wien 1963.

Alphons Lhotsky, Das Zeitalter des Hauses Österreich. Die ersten Jahre der Regierung Ferdinands I. in Österreich (Veröffentlichungen der Kommission für Geschichte Österreichs $4=$ Schriften des DDr. Franz Josef Mayer-Gunthof-Fonds 7) Wien 1971.

Hieronym Łopacıx́ski, Najdwniejscze slowniki polskie drukowane. Prace filologiczne V (1897) $1-61$.

R. P. Marcus, Tu melu besedishe treh jesikov. Das ist: Das kleine Wörterbuch in dreyen Sprachen ... Laibach 1781.

Dana Martínková, Alena Hadravová, J. Matl, Aeneae Silvii Historia Bohemica. Prag 1998.

Zdenĕk Masaǩ́ík, Die frühneuhochdeutsche Geschäftssprache in Mähren. Brünn 1985.

Maximilian I. Kaiser s. Weisskunig

Anton Mayer, Wiens Buchdrucker-Geschichte 1482-1882. Hrsg. von den Buchdruckern Wiens.1 (1482-1682). Wien 1883.

Anton Mayer, Die deutschen Lehnwörter im Tschechischen (Forschungen zur sudetendeutschen Heimatkunde 3) Reichenberg 1927.

Otto Mayer, Die Sternenwelt des Mittelalters. Graz 1993.

Ferdinand Menčrı, Rozmanitost. Přispěvky k dějinám stařsí české literatury 1. Jiěin 1880.

Ferdinand Menčrı, Prešpurský slovnik. Vocabularium latino-bohemicum Posoniense (Rozmanitosti. Př́spěvky k dějinám starši české literatury 2). Prag 1892.

Wolfgang Metzger, Die humanistischen, Triviums- und Reformationshandschriften der Codices Palatini latini in der Vatikanischen Bibliothek (Cod. Pal. lat. 1461-1914) (Kataloge der Universitätsbibliothek Heidelberg 4). Wiesbaden 2002.

Emanuel МıснÁLeк, Česka slovní zásoba v Klaretových slovnících. Prag 1989.

Franz Mıкцosıch, Etymologisches Wörterbuch der slavischen Sprachen. Wien 1886.

Heinrich Modern, Die Zimmern'schen Handschriften der K.k.Hofbibliothek. Ein Beitrag zur Geschichte der Ambraser Sammlung und der k. k. Hofbibliothek (JKhSW 20) Wien 1899

Hans Moser, Die Kanzlei Kaiser Maximilians I. Graphematik eines Schreibusus 1-2 (Innsbrucker Beiträge zur Kulturwissenschaft. Germanistische Reihe 5). Innsbruck 1977.

Johana Muchková, „Mythen vom Prager Deutsch“, Dipl.Arb. Prag 1995.

Johannes Mứler, Quellenschriften und Geschichte des deutschsprachigen Unterrichtes bis zur Mitte des 16. Jahrhunderts. Gotha 1882.

Konrad Müller, Die Goldene Bulle Kaiser Karls IV. Lateinischer Text mit Übersetzung (Quellen zur neueren Geschichte 25). Bern 1957.

Karl Nehring, Matthias Corvinus, Kaiser Friedrich III. und das Reich. Zum hunyadischhabsburgischen Gegensatz im Donauraum (Südosteuropäische Arbeiten 72). München 1975.

František Oberpfalcer, Jakost. Naše řě X/7 (1926) 193-200.

Andreas Felix Oefelius, Rerum Boicarum Scriptores nusquam antehac editi quibus vicinarum quoque gentium nec non Germaniae universae Historiae ex monumentis genuinis... II. Augsburg 1763. 
Zdeněk Opava, Bestseller in der frühen Neuzeit. Die verschiedenen Ausgaben des Gesprächsbüchleins von Ondřej Klatovský (1540), in: Die Volkssprachen als Lerngegenstand im Mittelalter und in der frühen Neuzeit. Akten des Bamberger Symposiums am 18. und 19. Mai 2001. Hrsg. von Helnut GuÜcK ( = Die Geschichte des Deutschen als Fremdsprache 3) Berlin - New York 2002, 57-66.

Ferdinand OpLL, Leben im mittelalterlichen Wien. Wien-Köln-Weimar 1998.

Franz (František) PalackÝ, Geschichte der Böhmen. Größtentheils aus Urkunden und Handschriften I-V. Prag 1836-1865.

Josef Pátr, Česká lexikografie. Struěný nástin dejin českého slovníkárstvi. Časopis pro moderni filologii 1 (1911) 6-10, 103-106.

Oskar Pausch, Italienisch-deutsche Ausspracheregeln aus dem Quattrocento, in: Ir sult sprechen willekomen. Grenzenlose Mediävistik. Festschrift für Helmut Birkнаn zum 60. Geburtstag. Hrsg. von Christa Tuczay, Ulrike Hirhager u. Karin Lichtblau. Bern usw. 1998, 132-138.

Oskar Pausch, Laurin in Venedig, in: Deutsche Heldenepik in Tirol. König Laurin und Dietrich von Bern in der Dichtung des Mittelalters. ... Hrsg. von Egon Kühebacher (= Beiträge der Neustifter Tagung 19'/ des Südtiroler Kulturinstituts) Bozen 1979, 192-211.

Oskar Pausch, Das älteste italienisch-deutsche Sprachbuch (DS Österr.Akad. Wiss., phil.-hist. Kl. 111 = Veröffentlichungen der Historischen Kommission 1).Wien 1972.

Oskar Pausch, Sprach- und Kulturgeschichtliches aus Mondsee. Der CVP 901 (12./13. Jahrhundert). MIÖG 80 (1972) 398-408.

Oskar Pausch, Lateinisch-deutsch-tschechische Vokabulare für Habsburger Regenten im 15. Jahrhundert, in: Die Volkssprachen als Lerngegenstand im Mittelalter und in der frühen Neuzeit. Akten des Bamberger Symposiums am 18. und 19. Mai 2001. Hrsg. von Helnut Glück ( = Die Geschichte des Deutschen als Fremdsprache 3) Berlin - New York 2002, 21-36.

Silvia Petrin, Geschichte von Maria Enzersdorf. Wien 1979.

Silvia Petrin, Perchtoldsdorf im Mittelalter. Forschungen zur Landeskunde von Niederösterreich 18. Wien 1969

Joannes Ptaśñk, Cracovia impressorum XV et XVI saeculorum (Monumenta Poloniae typographica XV et XVI seculorum I) Lemberg 1922.

Quellen zur Geschichte der Stadt Wien II, 2-3, bearb.von Karl UhliRz. Wien 1900-1904

QuelLen zur Geschichte der Stadt Wien IV,1, bearb. von Josef Lampel. Wien 1917.

Dietrich Reichling, Johannes Murmellius. Sein Leben und seine Werke. Nebst einem ausführlichen bibliographischen Verzeichniß sämtlicher Schriften und einer Auswahl von Gedichten. Freiburg/B. 1889.

Christine Reinle, „Id tempus solum“. Der Lebensentwurf Herzogs Johann von MosbachNeumarkt $(\dagger$ 1486) im Spannungsfeld von dynastischem Denken, kirchlicher Karriere und gelehrten Interessen, in: H. J. Becker, Der Pfälzer Löwe in Bayern. Zur Geschichte der Oberpfalz in der kurpfälzischen Epoche (= Schriften der Universität Regensburg 24) Regensburg 1997, 157-199.

Res litteraria Hungariae vetus operum impressorum 1473-1600 (= Régi Magyarországi nyomtatványok). Budapest 1971. 
Marianne Reuter, Die Handschriften der Universitätsbibliothek München V: Die lateinischen Handschriften aus der Quartreihe. Wiesbaden 2000.

Sigmund Riezlern, Geschichte Baierns 3 (Von 1347 bis 1508). Gotha 1889.

Mario Roques, Un modele de conversation pour la réception d'envoyé royal au XVe siècle, in: Festschrift Ernst Tappolet. Basel 1935, 261-263

Mario Roques, Recueil général des lexiques français du moyen âge (XIIe - XVe siécle) 1 (Bibliothèque de l'Ecole des Hautes Etudes. Sciences historiques et philol. 264) Paris 1936

Alda Rossebstiano, I „Dialoghi“ di Giorgio da Nurimbergo. Savigliano 1984.

Alda Rossebastiano, La tradition des manuels polyglottes dans l'enseignement des langues, in: History of the Language Sciences = Geschichte der Sprachwissenschaften 1/1. BerlinNew York 2000, 688-698.

Alda Rossebastiano, Antichi vocabolari plurilingui d'uso popolare. De Gulden Passer 55 (1977) $67-153$

Alda Rossebastiano, Antichi vocabolari plurilingui d'uso popolare: la tradizione del „Solenissimo Vochabuolista“. Alessandria 1984.

Alda Rossebastiano, Deutsch-italienische Vokabulare des 15. Jahrhunderts, in: Die Volkssprachen als Lerngegenstand im Mittelalter und in der frühen Neuzeit. Akten des Bamberger Symposiums am 18. und 19. Mai 2001. Hrsg. von Helnut GLücK ( = Die Geschichte des Deutschen als Fremdsprache 3) Berlin - New York 2002, 1-19.

Hans Rupprich, Das Wiener Schrifttum des ausgehenden Mittelalters (SB Österr. Akad. Wiss., Phil.-hist. Kl.228/5) Wien 1954.

José Ruysschaert, Les manuscrits corviniens de la Vaticane. Revue Française d'histoire du livre N.S. 36 (1982) 287-302.

Bohumil Ryba, Quelques mots sur le fragment no 554/zl. Prag 1968. 5 S. Typoskript. Als Beilage zum Fragment 554/zl der Klosterbibliothek Prag-Strahov.

Roland Schäffer, Die Baumkirchnerfehde (1469-71) in: Andreas Baumkirchner und seine Zeit (= Wissenschaftliche Arbeiten aus dem Burgenland 67) Eisenstadt 1983, 151-!82.

Karl Schalk, Mödlinger Grundbücher aus dem XV. Jahrhundert. Jahrbuch für Landeskunde von Niederösterreich 10 (1911) 181-229.

Johann Evangelist Schlager, Wiener Skizzen des Mittelalters, N.F. III. Wien 1846.

Julius von Schlosser, Elfenbeinsättel des ausgehenden Mittelalters (JKhSW 15) Wien 1894, $260-294$.

Josef Andreas Schmeller, Bayerisches Wörterbuch. 2. Aufl. bearb. von G. Karl Frommann 1-2. München 1872-77.

Franziska Schmid, Eine neue Fassung der maximilianeischen Selbstbiographie. Diss. Wien 1950 .

Ludwig Erich Sснмптт, Sprachgeschichte des Thüringisch-Obersächsischen iim Spätmittelalter. Die Geschäftssprache von 1300 bis 1500 (Entstehung und Struktur der „neuhochdeutschen Schriftsprache“ 1 = Mitteldeutsche Forschungen 36/1). Köln-Graz 1966.

Karl Julius SchröER, Lateinisch-deutsches Vocabular des XV. Jahrhunderts (Jahresprogramm der öffentlichen Ober-Realschule der k. Freistadt Preßburg 9). Preßburg 1859

Johann Schröpfer, Hussens Traktat „Orthographia Bohemica“. Die Herkunft des diakriti- 
schen Systems in der Schreibung slavischer Sprachen und die älteste zusammenhängende Beschreibung slavischer Laute (Slavistische Studienbïcher IV). Wiesbaden 1968.

Ludwig Schuba, Die medizinischen Handschriften der Codices Palatini Latini in der Vatikanischen Bibliothek (Kataloge der Universitätsbibliothek Heidelberg 1). Wiesbaden 1981.

Schultz, Alwin s. Weisskunig

Ilse Schunke, Die Einbände der Palatina in der Vatikanischen Bibliothek, Bd. 1-3 (Studi e testi 216-218). Città del Vaticano 1962.

Ernst Schwarz, Volkstumsgeschichte Böhmens, T.1 Böhmen (Handbuch der sudetendeutschen Kulturgeschichte 3) München 1965.

Karl Schwarzenberg, Die böhmischen Herrscherbilder, in: Genealogica et Heraldica = 10. Internationaler Kongreß für genealogische und heraldische Wissenschaften. Wien 1970, 667-671.

Karl Schwarzenberg, Katalog der kroatischen, polnischen und tschechischen Handschriften der Österreichischen Nationalbibliothek. Wien 1972 (Museion N.F. 4/4)

Jean Shaw, The printed dictionaries in France before 1539. (Database) Toronto 1997.

Alena S̆ıneČKová, Zur individuellen tschechisch-deutschen Zweisprachigkeit in Böhmen. Eine Fallstudie des 16. Jahrhunderts. Acta Universitatis Carolinae. Philologica 2 und $5=$ Germanistica Pragensia XII/XIII (1994 und 1996) 109-117 bzw. 93-103.

Alena ŠımečKová, Zum Dialog im tschechisch-deutschen Gesprächsbuch von Ondřej Klatovský, in: Die Volkssprachen als Lerngegenstand im Mittelalter und in der frühen Neuzeit. Akten des Bamberger Symposiums am 18. und 19. Mai 2001. Hrsg. von Helnut GLÜCK ( = Die Geschichte des Deutschen als Fremdsprache 3) Berlin - New York 2002, $67-76$.

Horst J. Simon, Zur Problematik einer Geschichte der deutschen Abtönungspartikeln. Fallstudien anhand eines Sprachlehrbuchs von 1424. Sprachwissenschaft 21 (1996) 262-300.

Emil Skála, Die deutsche Sprache auf dem Gebiet der Tschechoslowakei bis 1650. Acta Universitatis Carolinae philologica, Germanistica Pragensia IX (1984) 7-28.

Emil SkÁla, Zur Verbreitung der mittelhochdeutschen Diphthongierung und Monophthongierung. Acta Universitatis Carolinae Philologica 3 = Germanistica Pragensia X (1991) $7-18$.

Emil Skála, Deutsch und Tschechisch im mitteleuropäischen Sprachbund, in: Michael Berger/Kurt Krolop: Brücken (= Germanistisches Jahrbuch 1991/92). Berlin-PragPrerau 1992, 173-179.

Emil Skála, Das Prager Deutsch des 16. Jahrhunderts in: Festschrift für Hans EGgers zum 65. Geburtstag (= Beiträge zur Geschichte der deutschen Sprache und Literatur 94 Sonderheft). Tübingen 1972, 283-305.

Emil Skála, Lexikographie in Böhmen im XIII.-XIX. Jahrhundert, in:

Festschrift für Herbert Kolb, hrsg. von Klaus Matzel und Hans Gert Roloff.Bern 1989, 692-701.

Emil SkÁla, Tschechisch.deutsche Sprachkontakte. Acta Universitatis Carolinae. Philologica $2=$ Germanistica Pragensia XII (1994) 7-21.

SLovník středověké latiný v českých zemích. Latinitatis medii aevi Lexicon Bohemorum. ... Československá Akademie vĕd. Prag 1977 ff. 
Július Sopko, Codices latini medii aevi bibliothecarum Slovaciae $=$ Stredoveké latinský kódexy v Slovenských knižniciach (Codices medii aevi qui in bibliothecis Slovaciae asservantur ac olim asservabantur I) Martin 1981

Enikö Spenner, Das geistige Leben in Pest und Buda um die Wende vom 15. zum 16. Jahrhundert, in: G. BIEGEL, Budapest im Mittelalter (Schriften des Braunschweigischen Landesmuseums 62) Braunschweig 1991, 315-332.

StARoČEsKÝ slovník. Prag $1977 \mathrm{ff}$.

Karel Stejskal - Petr Voit, Illuminované rukopisy doby husitské. Prag 1990.

Gustav Strakosch-Gassmann, Erziehung und Unterricht im Hause Habsburg 1. Wien 1903 (Separatabdruck aus dem 5. Jahresbericht des städtischen Real-Gymnasiums in Korneuburg).

Laurenz Strebl, Zu Schreibung, Sprache und Kulturleben in Klosterneuburger Rechnungsbüchern. Wien Diss. 1956.

Juan Angel de Sumarán, Gramatica y pronunciación alemana y espaňiola, espaňiola y alemana, Teutsche vnd Spanische, Spannische vnd Teutsche Grammatica vnd außsprach. Vienna de Austria: Miguel Riccio Impressor 1634.

Jana Syrová, Sprachanalyse des Buches der Prager Malerzeche im Vergleich mit dem Prager Deutsch des 14. Jahrhunderts. Dipl. Arb. Prag 1981.

Károly Száthmáry de Péterfalva, Vitéz Holubár Wenczel lovag története viggal-elegy szomoru hösköltemény vi énekben. Budapest 1887.

József Szinnyei, Magyar írók élete és munkái 10 .Budapest 1905 (Nachdruck 1980/81).

Robert Tanzmeister, Die Habsburger und ihre Sprachen. Quo vadis Romania? 2 (1993) $52-67$

Bruno Thomas - Ortwin Gamber, Katalog der Leibrüstkammer, 1. Der Zeitraum von 500 bis 1530 (Führer durch das Kunsthistorische Museum 13) Wien 1976.

Wáclaw Wladiwoy Toмeк, Dejepis mesta Prahy II. VIII (Spisů musejnich LI = Nowočeská bibliothéka XVIII). Prag 1871.1891.

Wáclaw Wladiwoy Toмeк, Základy stáreho miestopisu Pražského I-V. Prag 1866-1875.

Paul Uiblein, Die Universität Wien im 14. Und 15. Jahrhundert, in: Das alte Universitätsviertel in Wien, 1385-1985. (= Schriftenreihe des Universitätsarchivs 2) Wien 1985, $17-36$.

Jakob Unrest, Österreichische Chronik. Hrsg. von Karl Grossmann (Monumenta Germaniae Historica. Scriptores Rerum Germanicarum N.S. 11) Weimar 1957

Urkunden und Actenstücke zur österreichischen Geschichte im Zeitalter Kaiser Friedrichs III. und König Georgs von Böhmen (1440-91) hrsg. von Ad. Bachmann. Wien 1879 (FRA Dipl. 42)

Josef VinTr, Das Tschechische. Hauptzüge seiner Sprachstruktur in Gegenwart und Geschichte (Slavistische Beiträge 403 = Studienhilfen 11). München 2001.

Georg Voigt, Enea Silvio Piccolomini als Papst Pius II. und sein Zeitalter 1-3. Berlin 1856 1863.

Volkssprachen - Die Volkssprachen als Lerngegenstand im Mittelalter und in der frühen Neuzeit. Akten des Bamberger Symposiums am 18. und 19. Mai 2001. Hrsg. von 
Helmut Glück ( = Die Geschichte des Deutschen als Fremdsprache 3) Berlin - New York 2002.

Ernst Voullí́me, Die Inkunabeln der königlichen Bibliothek und der anderen Berliner Sammlungen. Beihefte zum Zentralblatt für Bibliothekswesen XXX. Leipzig 1906.

Eduard Wagner - Zoroslava Drobná - Jan Durdík, Tracht, Wehr und Waffen des späten Mittelalters (1350-1450) Prag 1957.

Der Weisskunig. Nach den Dictaten und eigenhändigen Aufzeichnungen Kaiser Maximilians I. zusammengestellt von Marx Treitzsauerwein von Ehrentreitz, hrsg. von A. Schultz (JKhSW 6). Wien 1888.

Weisthǜner - Die tirolischen Weisthümer... hrsg. von Ignaz von Zingerle und K. Theodor von Inama-STernegg. II. Oberinnthal (Österreichische Weisthümer 3, II) Wien 1877

B. Widmer, Enea Silvio Piccolomini. Papst Pius II. Ausgewählte Texte aus seinen Schriften. Basel-Stuttgart 1960.

Hermann Wiesflecker, Kaiser Maximilian I. Das Reich, Österreich und Europa an der Wende zur Neuzeit 1-5. Wien 1971/86.

Friedrich WiLken, Geschichte der Bildung, Beraubung und Vernichtung der alten Heidelberger Büchersammlungen. Ein Beitrag zur Literärgeschichte des 15. Und 16. Jahrhunderts. Nebst einem Verzeichniße. Heidelberg 1817.

Thomas Winkelbauer, Fürst und Fürstendiener. Gundaker von Liechtenstein, ein österreichischer Aristokrat des konfessionellen Zeitalters (MIÖG, Ergbd. 34) Wien-München 1999.

Bedřiška Wižǐálková, Nejstarší známý tištěný vokabulář. Miscelanea oddělení rukopisů a vaácných tiski̊ 1 (1971) II, 1-160.

WörTERBuch der bairischen Mundarten in Österreich Hrsg. vom Institut für österreichische Dialekt- und Namenlexika (Bayerisch- österreichisches Wörterbuch I. Österreich) Wien $1963 \mathrm{ff}$.

WörTERBuch - Sudetendeutsches Wörterbuch. Wörterbuch der deutschen Mundarten in Böhmen und Mähren-Schlesien. Hrsg. von Heinz Engels und Otfrid Ehrismann. München $1988 \mathrm{ff}$.

Philippe WolfF, Sprachen, die wir sprechen. Ihre Entwicklung aus dem Lateinischen und Germanischen von 100-1500 n. Ch. München 1971.

Rudolf Wolkan, Geschichte der deutschen Literatur in Böhmen bis zum Ausgange des 16. Jahrhunderts Prag 1894.

Gregor Wolny, Bericht über Ch. d'Elverts Geschichte und Beschreibung der königl. Kreisund Bergstadt Iglau in Mähren und dessen historische Literatur-Geschichte von Mähren und Österreichisch-Schlesien (SB Akad. Wiss., phil.-hist. Kl.6). Wien 1851, 26-44.

Gregor Wolny, Bericht über den historischen Vorrath im Archive des Benediktiner Stiftes Raigern in Mähren. AfÖG 1/5 (1848) 147-165.

Caspar Zacharias Wussin, Lexicon tripartitum oder Teutsch-Lateinisch und Böhmisches Wörter-Buch.... Dritte Auflage. Prag 1742.

Isidor Theodor ZAHRADnik, Slovník latinsko-německo-český pro Ladislava Pohrobka (Archiv pro lexikografii a dialektologii 5). Prag 1904.

Georg Zappert, Über ein für den Jugendunterricht Kaiser Maximilians abgefaßtes lateinisches Gesprächsbüchlein (SB Österr. Akad. Wiss., phil.-hist. Kl. 28).Wien 1858. 
